\title{
Effects of pollution on holdfast macrofauna of the kelp Ecklonia radiata: discrimination at different taxonomic levels
}

\author{
Stephen D. A. Smith, Rodney D. Simpson \\ Zoology Department, University of New England, Armidale, New South Wales 2351, Australia
}

\begin{abstract}
Non-metric multidimensional scaling (MDS) ordinations were conducted at 5 main taxonomic levels and 1 mixed level (corresponding to major faunal groups) for community data from kelp holdfasts sampled across a gradient of domestic effluent at Coffs Harbour, New South Wales, Australia. All plots showed separation of close outfall sites from controls. Two-way nested analysis and pairwise comparisons of locations using non-parametric randomisation tests (ANOSIM) indicated that differences between the close outfall location and controls were significant at all taxonomic levels. In contrast, the effect due to sites within locations, although significant up to order, was not significant for analyses at the mixed, class and phylum levels. These observations support the hypothesis that anthropogenic effects modify community structure at higher taxonomic levels than natural environmental variables. Consequently, studies of impact that focus on higher taxa may be more readily interpretable than those conducted at the species and family levels.
\end{abstract}

\section{INTRODUCTION}

The aggregation of species to higher taxonomic levels without the loss of substantial discriminatory power has been well documented for studies of anthropogenic effects on benthic infauna (Gray et al. 1988, 1990, Heip et al. 1988, Herman \& Heip 1988, Warwick 1988a, b, 1993, Austen et al. 1989, Ferraro \& Cole 1990, Warwick et al. 1990b). In some examples using multidimensional scaling (MDS) ordinations, differences have been detected at the phylum level which relate more closely to the pollution gradient than equivalent analyses at lower taxonomic levels (Warwick 1988b, Gray et al. 1990). A tentative explanation for this observation is that anthropogenic effects may modify community structure at taxonomic levels higher than those at which substantial natural background variation occurs - the latter processes tending to have an effect through species replacement (Warwick 1988a, b). An extrapolation of this suggestion is that the effects of potentially confounding natural variability may be reduced in studies of perturbation if analyses are conducted at the family level or higher.
To date most studies reporting successful discrimination at higher taxonomic levels, although including a range of anthropogenic disturbances, have focused on the fauna (macro- and meiofauna) of soft sediments. Tests of the wider application of the concept to other community types are few (e.g. coral communities and the effects of an El Niño event; Warwick et al. 1990a).

This paper presents the results of non-metric MDS ordinations of holdfast macrofaunal community data sampled along a gradient of domestic pollution at Coffs Harbour, New South Wales, Australia (Fig. 1). A difference in community structure has already been demonstrated using MDS at the species level, with sites closest to the outfall separating from other sites at all sample times (Smith \& Simpson 1992). The application of the taxonomic aggregation procedures previously described for benthic infauna to the holdfast data provides a further test of the general utility of the method. In addition, it can also be viewed as part of a cost-benefit evaluation for future studies of impact in a region where the fauna are poorly known and sorting to higher taxa would result in considerable time savings.

One of the problems associated with the analysis of data from the holdfast macrofaunal community is the 


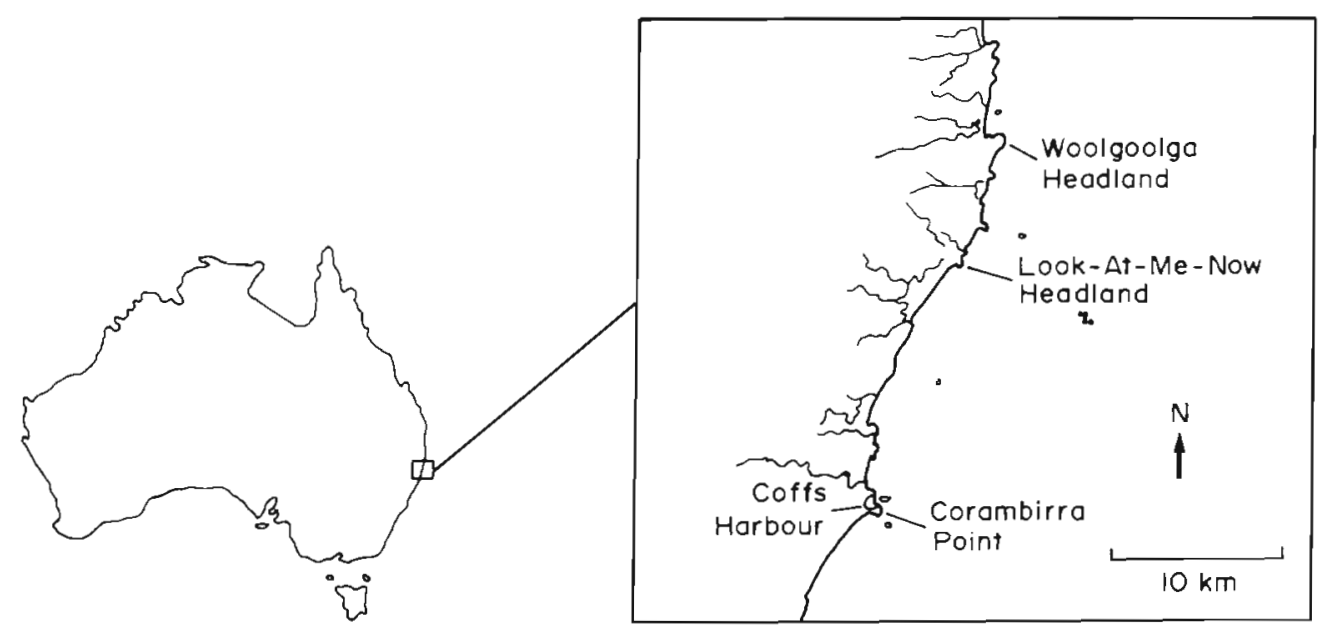

Fig 1 Location of the

variation in size (or volume) of each replicate sample. Whereas this variable is controlled in infaunal studies, holdfast volume is not readily measurable in situ. Thus although holdfasts for this study were randomly sampled from mature kelp plants only (Stage 3; Kirkman 1981), holdfast volumes ranged from 18 to $288 \mathrm{ml}$. This does not pose insurmountable problems for univariate analyses as the effects of volume can be regressed out using analysis of covariance (ANCOVA) (Underwood 1981, Clarke \& Green 1988). However, the effects of uncontrolled nuisance variables are not as easy to assess in multivariate procedures such as ordination (Clarke \& Green 1988).

The differences in volume are likely to be reflected both in numbers of individuals and species in the sample. Standardisation of the abundance data (to proportions of the total number of individuals) can be used to correct for differences in absolute abundance (Field et al. 1982, Clarke 1993) but for analyses which are influenced by the number of species in each sample, differences in volume may pose a considerable problem. There is a significant positive correlation between holdfast volume and species number (unpubl. data) and thus larger samples are more likely to have more species in common with other large holdfasts than smaller ones. Although the similarity measure used in these analyses (the Bray-Curtis measure; Bray \& Curtis 1957) gives more weight to common species (Field et al. 1982), the presence of a greater number of species in larger samples is likely to influence the computed proximities among samples within the resulting matrix. This is particularly so where data are transformed as more species are considered in the calculation of proximity values (Clarke \& Green 1988). To further compound this problem, holdfasts taken from sites adjacent to the outfall are generally smaller than those from control sites (although ages as determined by the examination of stipe growth rings (Novacek 1981) are comparablel. We postulate that aggregation to higher taxa may reduce this potentially confounding source of variability, uncommon species becoming less important as they are absorbed into higher taxonomic groups. This hypothesis is examined by superimposing holdfast volumes on the MDS plots for each taxonomic level (i.e. overlay technique; Field et al. 1982, Gray et al. 1990).

Univariate analyses of holdfast data have shown differences between close outfall sites and control sites for a number of variables (Smith \& Simpson 1992). One of these is the ratio of amphipods to polychaetes. This derived variable represents a ratio between 2 faunal groups defined at different taxonomic levels. The success of this measure in discriminating between sites indicates that changes within the holdfast community resulting from the outfall are detectable using higher taxa. It also suggests that MDS analyses using data at mixed taxonomic levels may be informative, if organisational changes resulting from anthropogenic perturbations are not focused at any specific systematic level. This concept is explored by conducting MDS on data which are aggregated to major faunal groups, i.e. through the analysis at the class level with the crustacean class Malacostraca subdivided into its component orders

\section{METHODS}

Samples were taken along a putative gradient of domestic effluent resulting from the Coffs Harbour city outfall. A nested sampling design was employed with 3 sites nested within each of 4 locations (Figs. 2 to 4 ). Location (Loc) 1 is closest to the outfall, Loc 2 is at the same headland but more distant from the outfall and Locs 3 and 4 are control locations 15 and $20 \mathrm{~km}$ north of the outfall respectively [details of the study sites, effluent quality and nearshore features are provided in a previous paper, Smith \& Simpson (1992)]. In line with recent recommendations to avoid problems in inter- 


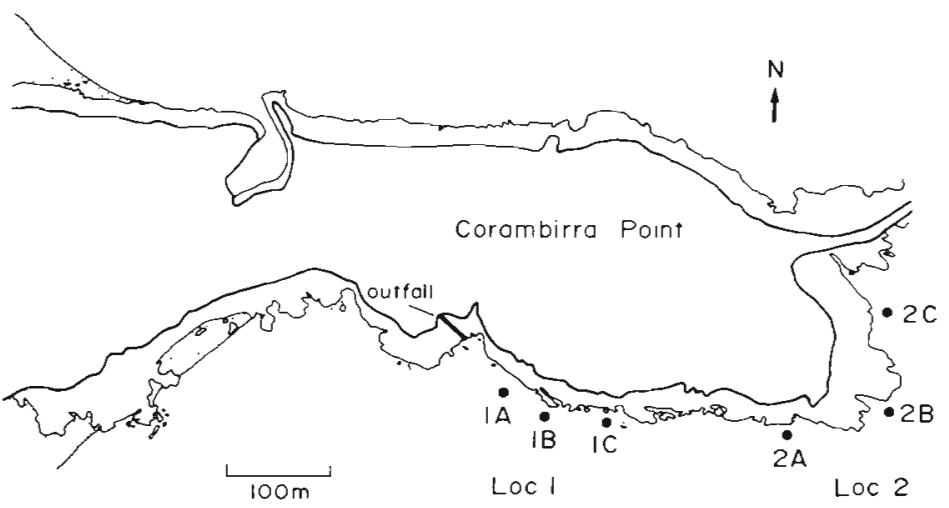

Fig. 2. Corambirra Point (Locs 1 and 2) showing holdfast sampling sites and outfall position

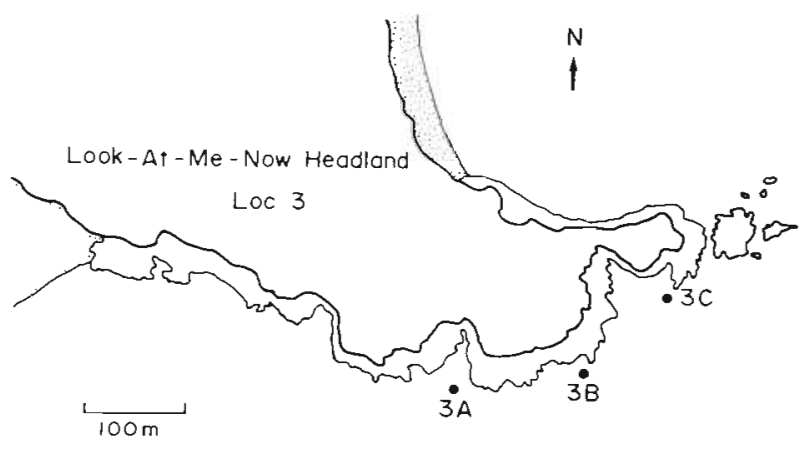

Fig. 3. Look-at-me-now Headland (Loc 3) showing holdfast sampling sites

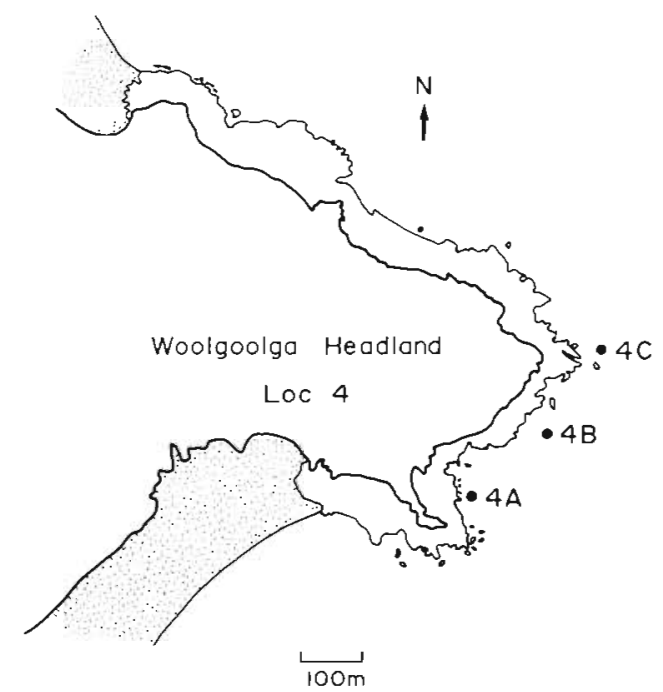

Fig. 4. Woolgoolga Headland (Loc 4) showing holdfast sampling sites

preting results due to confounding with untested alternative hypotheses (Hurlbert 1984, Underwood 1991), all sites have similar topographies and exposure and the design incorporates 2 control sites. However, the lack of suitable locations to the south of Corambirra
Point precluded the establishment of controls both to the north and south of the outfall.

Samples used in the analyses reported in this paper were taken in August 1991 (winter). Five replicate holdfasts were randomly sampled at each of the 12 sites from a depth of 5 to $6 \mathrm{~m}$ (depths measured from MHWS). Holdfast volumes were determined using water displacement and all macrofauna were removed and identified to the lowest taxonomic level possible. Frequencies were determined for each species and these data were aggregated to provide counts for family, order, class and phylum (216 'species', 112 families, 37 orders, 17 classes and 10 phyla the final species count has not been determined at this stage owing to taxonomic difficulties with some groups). Raw abundance data were standardised and double-square-root transformed prior to computation of similarities using the Bray-Curtis measure. Non-metric MDS analyses were conducted on the resultant similarity matrices to generate 2-dimensional plots. In order to determine if there were significant differences among sites within locations and also among locations at each taxonomic level, 2-way nested analyses were performed using the non-parametric analysis of similanties (ANOSIM) procedure (Clarke 1993). For these analyses control locations were combined as 1 treatment level (i.e. 6 sites nested within 1 control location). This not only increased the number of permutations possible (and therefore statistical power) for pairwise comparisons between the 2 outfall locations and controls but also more closely fitted the experimental model of 3 treatment levels (close outfall, more distant outfall and no outfall).

Two methods were used to determine which taxa were primarily responsible for differences among locations, discriminant function analysis (DFA) and the similarity percentages (SIMPER) procedure (Warwick et al. 1990a, Clarke 1993). DFA is a parametric method which distinguishes between a priori defined groups using linear combinations of the variables. The procedure finds discriminant functions which account for as much of the variability between the groups as possible. Correlation analysis between the discriminant functions and the biological variables can then be conducted to determine which taxa (in this case) are primarily responsible for the differences among groups. In order to make the DFA consistent with the other analyses (MDS and ANOSIM), comparisons were made using standardised data with the same 3 treatment levels as the a priori groups - Loc 1, Loc 2 , and Locs 3 and 4 combined. SIMPER determines which taxa are the most important contributors to the BrayCurtis similarity measure and are thus primarily re- 
sponsible for similarity within groups and dissimilarity between groups of replicate samples (Warwick et al. 1990a, 1991, Clarke 1993).

\section{RESULTS}

The results of MDS ordination for the 5 main taxonomic levels and the mixed data are shown in Fig. 5. Although the relationship of sites does not show dis- tinct clustering, close outfall sites (i.e. those sites within Loc 1 - Sites $1 \mathrm{~A}, 1 \mathrm{~B}$ and $1 \mathrm{C}$ ) tend to separate from replicates from other sites at each level. Replicates from Site $2 \mathrm{~A}$ (the site within Loc 2 closest to the outfall) are intermediate between samples from Loc 1 and those from sites more distant from the outfall. In interpreting the plots it should be emphasised that sites were separated by relatively small distances (Figs. 2 to 4 ) and as a consequence, groupings of site data are unclear. To
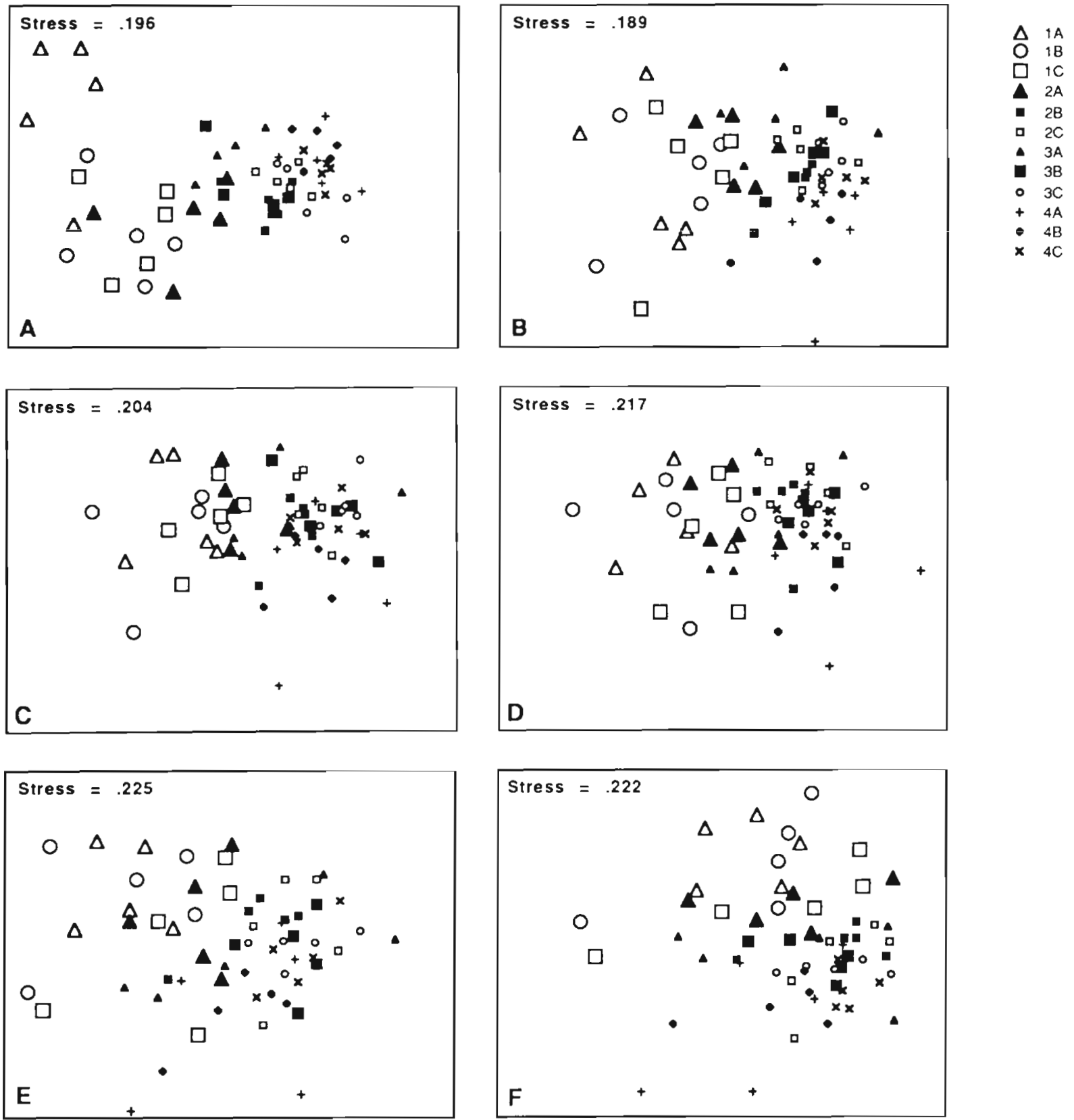

Fig. 5. MDS plots for holdfast community data (standardised and double square-root transformed) aggregated to different taxonomic levels. (A) Species; (B) family; (C) order; (D) mixed; (E) class; (F) phylum. Samples from each site are represented by the same symbols in each plot (a key to these symbols is shown next to Plot B). Mixed taxonomic analysis was conducted at the class level with the crustacean class Malacostraca subdivided into component orders 


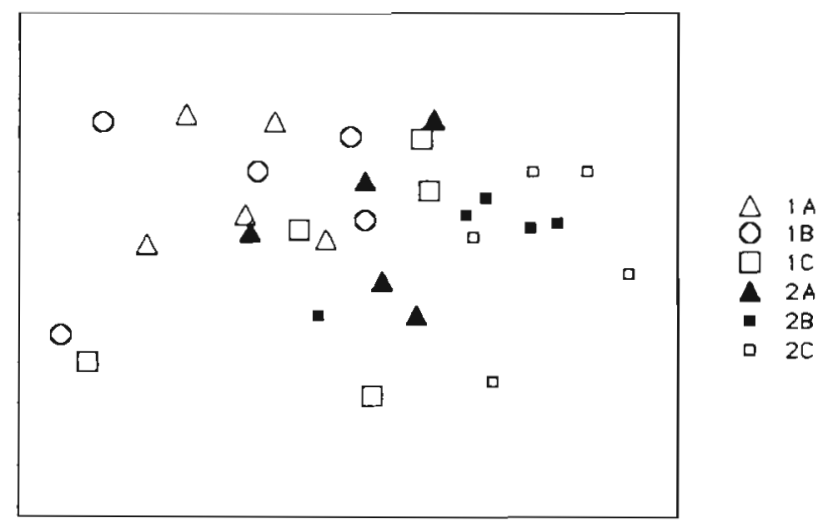

Fig. 6. MDS plot for data aggregated to class (replicates from Locs 1 and 2 only) showing an apparent gradient of effect. Sites adjacent to the outfall are to the left and more distant sites are to the right of the plot

clarify the gradient along Corambirra Point, the plot for data aggregated to class but omitting the control sites (i.e. showing only Sites $1 \mathrm{~A}$ to $2 \mathrm{C}$ ) is shown in Fig. 6. Sites adjacent to the outfall tend to cluster to the left with a transition to the more distant sites at the right of the plot.

A feature of all the plots is their high stress value. Stress is a measure of how well the 2-dimensional MDS solution portrays the relationship between the data points, high values $(>0.2)$ indicating that care needs to be taken in interpreting the apparent MDS pattern (Clarke \& Green 1988, Clarke 1993). In the present case, aggregation above the family level results in stress values exceeding 0.2 . The results of the 2-way nested ANOSIM help to clarify the relationship between samples and confirm the apparent differences between Loc 1 and other locations at all taxonomic levels. Table 1 presents the results of the ANOSIM for each taxonomic level including effects for sites within location, location and pairwise comparisons between the treatments. At all levels there is a highly significant difference among locations and also

Table 1. Results of 2-way nested ANOSIM and pairwise comparisons of locations for each level of taxonomic aggregation

\begin{tabular}{|c|c|c|c|c|}
\hline Taxonomic level & Effect & $\mathrm{R}$ & Size of sample & Significance \\
\hline \multirow[t]{5}{*}{ Species } & Site within location & 0.429 & 1000 & 0.001 \\
\hline & Location & 0.400 & 1000 & 0.007 \\
\hline & Loc 1 vs Loc 2 & 0.410 & 10 & $0.100^{11}$ \\
\hline & Loc 1 vs Locs $3+4$ & 0.770 & 84 & 0.012 \\
\hline & Loc 2 vs Locs $3+4$ & 0.050 & 84 & 0.226 \\
\hline \multirow[t]{5}{*}{ Family } & Site within location & 0.202 & 1000 & 0.001 \\
\hline & Location & 0.471 & 1000 & 0.002 \\
\hline & Loc 1 vs Loc 2 & 0.780 & 10 & $0.100^{\mathrm{a}}$ \\
\hline & Loc 1 vs Locs $3+4$ & 0.880 & 84 & 0.012 \\
\hline & Loc 2 vs Locs $3+4$ & 0.080 & 84 & 0.167 \\
\hline \multirow[t]{5}{*}{ Order } & Site within location & 0.110 & 1000 & 0.017 \\
\hline & Location & 0.446 & 1000 & 0.003 \\
\hline & Loc 1 vs Loc 2 & 0.810 & 10 & $0.100^{d}$ \\
\hline & Loc 1 vs Locs $3+4$ & 0.860 & 84 & 0.012 \\
\hline & Loc 2 vs Locs $3+4$ & 0.020 & 84 & 0.369 \\
\hline \multirow[t]{5}{*}{ Mixed } & Site within location & 0.056 & 1000 & 0.105 \\
\hline & Location & 0.462 & 1000 & 0.004 \\
\hline & Loc 1 vs Loc 2 & 0.740 & 10 & $0.100^{t}$ \\
\hline & Loc 1 vs Locs $3+4$ & 0.870 & 84 & 0.012 \\
\hline & Loc 2 vs Locs $3+4$ & 0.080 & 84 & 0.238 \\
\hline \multirow[t]{5}{*}{ Class } & Site within location & 0.059 & 1000 & 0.154 \\
\hline & Location & 0.510 & 1000 & 0.004 \\
\hline & Loc 1 vs Loc 2 & 0.670 & 10 & $0.100^{\mathrm{d}}$ \\
\hline & Loc 1 vs Locs $3+4$ & 0.910 & 84 & 0.012 \\
\hline & Loc 2 vs Locs $3+4$ & 0.170 & 84 & 0.167 \\
\hline \multirow[t]{5}{*}{ Phylum } & Site within location & 0.054 & 1000 & 0.115 \\
\hline & Location & 0.486 & 1000 & 0.004 \\
\hline & Loc 1 vs Loc 2 & 0.560 & 10 & $0.100^{\mathrm{d}}$ \\
\hline & Loc 1 vs Locs $3+4$ & 0.850 & 84 & 0.012 \\
\hline & $\operatorname{Loc} 2$ v5 $\operatorname{Locs} 3+4$ & 0.130 & 84 & 0.191 \\
\hline
\end{tabular}



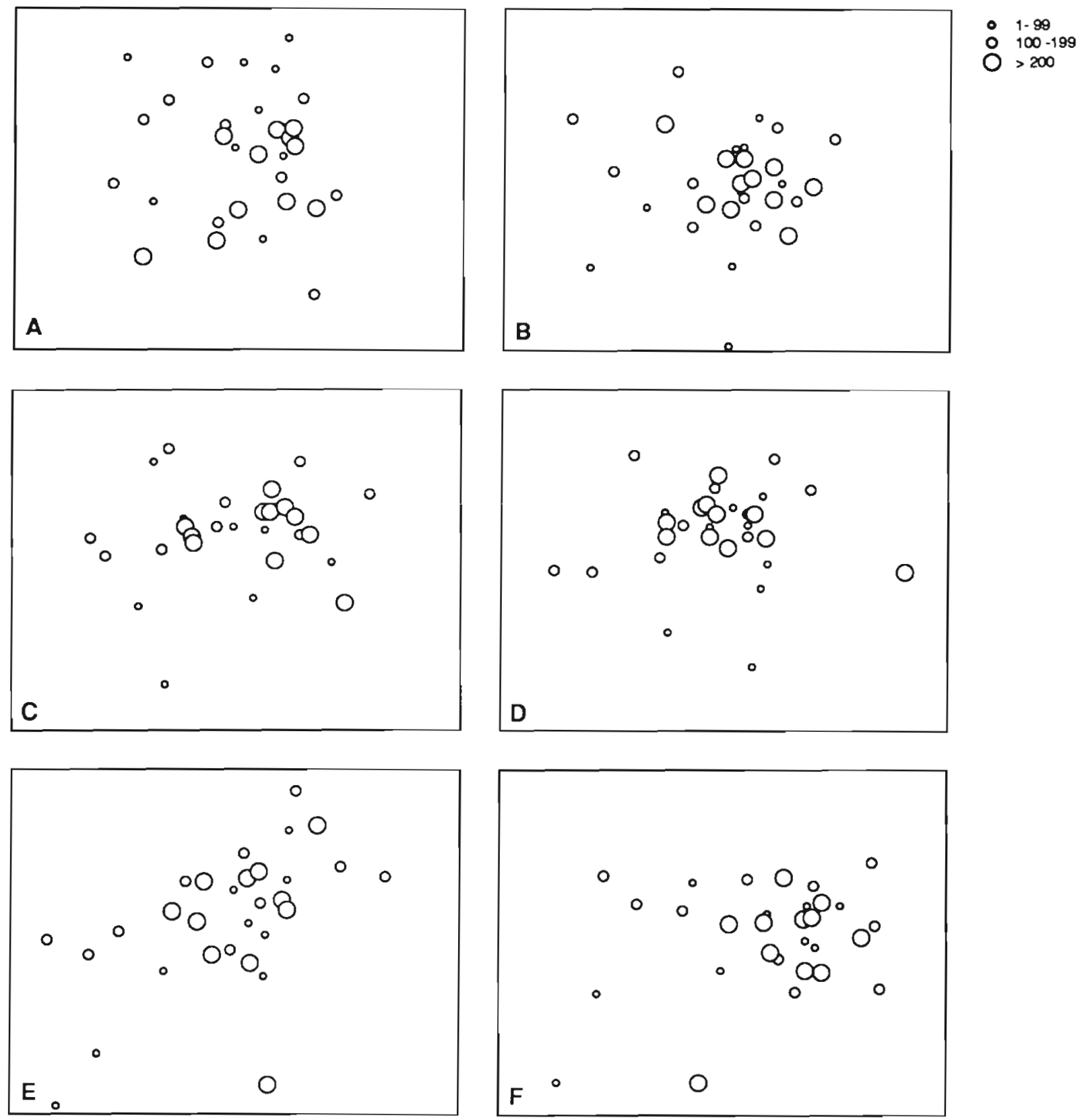

Fig. 7 MDS plots for each taxonomic level with symbols representing class of holdfast volume $(<99,100$ to 199 and $>200 \mathrm{ml})$ superimposed on the position of each replicate. Only data for the control sites (Locs 3 and 4 ) are presented. (A) Species; (B) family; (C) order; (D) mixed; (E) class; (F) phylum

between Loc 1 and the controls. Only 10 permutations are possible in the analysis for differences between Loc 1 and Loc 2 and so the test has low power. At all levels, the results for this effect show the minimum possible probability of 0.10 . There is no significant difference between Loc 2 and the controls at any level. The site within location effect is of considerable interest as it is highly significant up to the order level, but not significant in further aggregations. This would ap- pear to suggest that small-scale spatial effects are not as evident at higher levels.

The results of superimposition of holdfast volumes (in 3 classes: $<99,100$ to 199 and $>200 \mathrm{ml}$ ) are shown in Fig. 7. As the hypothesis under test is that there is a difference in the distribution of samples of different volumes at different taxonomic levels, the holdfast samples from Locs 1 and 2 have been omitted with the rationale that the effect of the outfall may confound the 
Table 2. Taxonomic groups showing a statistically significant correlation with the first canonical discriminant function in the DFA for order, class and phylum

\begin{tabular}{|llcc|}
\hline Taxonomic level & \multicolumn{1}{c}{ Variable } & I & P \\
\hline Order & Veneroidea & 0.365 & $<0.01$ \\
Class & Bivalvia & 0.555 & $<0.001$ \\
& Malacostraca & -0.305 & $<0.05$ \\
& Ophiuroidea & -0.277 & $<0.05$ \\
Phylum & Mollusca & 0.655 & $<0.001$ \\
& Crustacea & -0.380 & $<0.01$ \\
& Echinodermata & -0.339 & $<0.01$ \\
& Annelida & -0.294 & $<0.05$ \\
& & & \\
\hline
\end{tabular}

interpretation. Any real patterns resulting from biases due to differences in the number of species should be apparent by examining the data from the control locations.

None of the plots show a distinct clustering of holdfasts of the same volumetric class. This suggests that there is no obvious pattern of bias of holdfast volume in the computed similarities among sites at any of the taxonomic levels. Thus the method appears to be robust to the possible effects of differential succession for different taxonomic groups and general increases in species number with increasing volume.

DFA was conducted for the abundance data aggregated to order, class and phylum with 2 canonical discriminant functions generated for each analysis. A priori groupings were the same as for the ANOSIM: Loc 1 .
Loc 2, and Locs 3 and 4 pooled. The first discriminant function accounted for $79.8 \%$ of the variance for orders, $87.5 \%$ for classes and $85.1 \%$ for phyla. The variables which were significantly correlated with this discriminant function at each taxonomic level are listed in Table 2. Only 1 taxon showed a significant correlation for order with the first function, the bivalve group Veneroida. This group contains the species Lasaed australis which was previously identified as one of the indicators of effluent effect with large abundances at sites adjacent to the outfall (Smith \& Simpson 1992). In the analysis at the class level, bivalves are positively correlated and ophiuroid echinoderms and the malcostracan crustaceans negatively correlated with the first function. The analysis at the phylum level confirms the importance of these groups with significant correlations for molluscs (positive), crustaceans (negative) and echinoderms (negative) as well as for annelids (negative). Examination of the group means indicates that crustaceans, echinoderms and annelids have a lower dominance and bivalves a higher dominance adjacent to the outfall.

The results of the SIMPER breakdown were very similar to those for DFA. Table 3 lists the 6 taxa which contribute most to the differences between Loc 1 and the controls for order, class and phylum levels of aggregation. The mean proportion of each of these taxa at each location and the percentage contribution of each to the overall Bray-Curtis dissimilarity are also listed. As for the results from DFA, bivalves and ophiuroids contribute most to the dissimilarity at all levels

Table 3. Results of SIMPER breakdowns for each of the higher taxa. The 6 groups contributing most to the average dissimilarity between Loc 1 and the controls (Locs 3 and 4) are listed together with their percentage contribution to the overall dissimilarity and their dominance at each location (expressed as a proportion)

\begin{tabular}{|c|c|c|c|c|c|}
\hline & \multirow[t]{2}{*}{ Taxon } & \multicolumn{2}{|c|}{ Mean proportion } & \multirow{2}{*}{$\begin{array}{c}\text { Contribution } \\
(\%)\end{array}$} & \multirow{2}{*}{$\begin{array}{c}\text { Cumulative } \\
(\%)\end{array}$} \\
\hline & & Lor 1 & Controls & & \\
\hline \multirow{6}{*}{ Order } & Veneroidea & 0.18 & 0.00 & 10.21 & 10.21 \\
\hline & Myoida & 0.06 & 0.01 & 6.18 & 16.39 \\
\hline & Ophiuroidea & 0.00 & 0.03 & 5.64 & 22.03 \\
\hline & Tanaidacea & 0.00 & 0.02 & 4.78 & 26.81 \\
\hline & Terebellida & 0.02 & 0.03 & 4.46 & 31.27 \\
\hline & Pleurogona & 0.02 & 0.03 & 4.44 & 35.71 \\
\hline \multirow[t]{6}{*}{ Class } & Bivalvia & 0.30 & 0.05 & 12.29 & 12.29 \\
\hline & Ophiuroidea & 0.00 & 0.03 & 11.14 & 23.43 \\
\hline & Ascidiacea & 0.02 & 0.03 & 8.92 & 32.35 \\
\hline & Zoantharia & 0.02 & 0.01 & 8.37 & 40.72 \\
\hline & Cirripedia & 0.01 & 0.00 & 8.03 & 48.75 \\
\hline & Malacostraca & 0.14 & 0.36 & 7.53 & 56.28 \\
\hline \multirow[t]{6}{*}{ Phylum } & Mollusca & 0.31 & 0.05 & 16.42 & 16.42 \\
\hline & Echinodermata & 0.00 & 0.05 & 16.18 & 32.60 \\
\hline & Chordata & 0.02 & 0.03 & 12.53 & 45.13 \\
\hline & Cnidaria & 0.02 & 0.01 & 11.65 & 56.78 \\
\hline & Chelicerata & 0.01 & 0.00 & 10.23 & 67.01 \\
\hline & Crustacea & 0.16 & 0.36 & 10.09 & 77.10 \\
\hline
\end{tabular}


with a greater dominance of bivalves and a lesser dominance of ophiuroids at Loc 1 . In the analysis at the order level, proportions of Tanaidacea, the polychaete group Terebellida and ascidians comprising the Pleurogona (mainly Pyura stolonifera) are all less dominant adjacent to the outfall. Bivalves, ophiuroids and ascidians continue to provide the greatest contribution to dissimilarities in the analyses for class. In addition, the results indicate a lower dominance of Malacostraca and a higher dominance of anemones and barnacles at outfall sites. At the phylum level the same general trends are apparent with a greater dominance of Mollusca and Cnidaria and a lesser dominance of Echinodermata, Chordata and Crustacea at Loc 1. Chelicerata (pycnogonids) are also ranked within the 6 most discriminatory taxa with a higher dominance adjacent to the outfall. In contrast to the results of DFA, polychaetes were not highly ranked contributors to the dissimilarities between treatments at the phylum level.

\section{DISCUSSION}

Consistent differences between close outfall sites and more distant sampling sites are evident at all taxonomic levels, both in groupings within the MDS plots and in significant pairwise comparisons in the randomisation tests (ANOSIM). For the comparison between Loc 1 and the controls, a total of 84 permutations were possible and the minimum level of probability ( $\mathrm{p}=$ 0.012 ) was observed in the analyses at each taxonomic level. The increase in probability of the site within location effect from a highly significant value $(p=0.001)$ at the species level to non-significant values at levels higher than order indicates that small-scale spatial variation in the composition of the community is primarily manifest at these lower taxonomic levels. While there is also a significant location effect at lower taxonomic levels this continues through to the highest levels of aggregation. This observation provides support for the hypothesis that the assessment of perturbation at higher taxonomic levels may reduce confounding due to natural background variability and may more accurately reflect the effects attributable to perturbation (Warwick 1988b)

The lack of any obvious pattern of bias resulting from differences in holdfast volume is encouraging and indicates that the methods are robust to variations in this factor. The reason for this robustness is probably due, at least in part, to successional processes within the holdfast. There is a core of species which tends to dominate the habitat at all volumes (unpubl, data). In larger holdfasts, there is a greater number of other species but these tend to be added to the complement rather than replacing those already present. While there are changes in dominance of some species, the early colonisers are among the dominant taxa at all holdfast sizes, progressive habitat growth primarily resulting in an increasing number of rarer species. This pattern has also been reported for communities from other 'growing habitats' including invertebrates in the holdfast of Macrocystis pyrifera (Ojeda \& Santelices 1984). As the Bray-Curtis measure is weighted by the more abundant taxa (Field et al. 1982) it is likely that these species groups will be important in the determination of similarity between holdfasts of different volumes, despite heavy (double square-root) transformation of the data to force more species into the calculations (Clarke \& Green 1988). Nevertheless, in future studies it may be appropriate to reduce the variability associated with differences in holdfast size by using a stratified random sampling programme in which holdfast size, rather than growth stage (as in the present study), is considered as a qualifying variable.

The results of both DFA and SIMPER analyses indicate that differences between control sites and those adjacent to the outfall are primarily attributable to an increased proportion of small bivalves and a reduction in the proportion of ophiuroids, crustaceans and polychaetes. A reduction in both crustaceans and ophiuroids has been noted for other macrofaunal communities under the influence of effluent discharge (Rosenberg 1973, Hoare \& Hiscock 1974, Pearson \& Rosenberg 1978, Cross \& Ellis 1981). In addition, the increased abundance of suspension-feeding organisms including bivalves has already been documented for holdfast communities subjected to organic enrichment (Jones 1972, 1973, Smith \& Simpson 1992). The observation that polychaetes (annelids at the phylum level of aggregation) were reduced in dominance adjacent to the outfall is however contrary to previous work (Hoare \& Hiscock 1974, Pearson \& Rosenberg 1978). This observation may also reflect an artefact of the study, in that abundances per unit volume may be similar but as data were standardised and there was a large proportion of bivalves at the close outfall sites, proportions for polychaetes are reduced.

The results of this study extend the number of habitats in which the effects of perturbation can be demonstrated at taxonomic levels higher than species. In the present context, the implications for the continuing monitoring programme are that considerable time savings can be made in the sorting procedure enabling more samples to be processed for the same level of effort. The use of a mixed taxonomic approach would appear to be advantageous as variables are easily recognisable as distinct faunal groups (Warwick 1988b). The selection of which combinations of mixed taxa are to be included in the analysis may be aided using procedures such as DFA and SIMPER on data from pilot 
studies to determine which contribute most to the differences among sampling locations.

The success of these analyses in detecting differences among sites at higher taxonomic levels is also important in a regional context as the fauna in subtropical Australia are poorly known. This can often result in delays in identifying even the more common species in some taxa as keys are not widely available. However, while the approach of adopting lower taxonomic discrimination in the determination of perturbation in benthic communities is appealing for cost and thus management reasons, the reduction in taxonomic rigour in regions such as Australia will not help in addressing the relatively poor knowledge of local fauna. It may thus be necessary to reach a compromise between management and scientific objectives in the selection of appropriate levels of taxonomic discrimination in impact assessment programmes.

Acknowledgements. Most of the statistical procedures used in this study were conducted using the PRIMER computer programs from Plymouth Marine Laboratory, UK. Consequently, we thank Drs R. M. Warwick and K. R. Clarke for making both the software and documentation available. We also thank Dr S. Cairns for help with computing and additional statistical analyses, and Lynda Bridges and Becky Francis for preparing the figures. The following people are gratefully acknowledged for taxonomic assistance: Dr P. Hutchings (polychaetes), Dr J. Lowry and Ms H. Stoddart (amphipods), Mr D. Staples (pycnogonids), Dr G. Poore (isopods), Mr I. Loch, Mr P. Colman, Mr D. Tarrant and Dr W. Ponder (molluscs), Dr A. Bruce (caridean shrimps) and Dr F. Rowe (echinoderms). The work was conducted as part of a monitoring programme under contract to the Public Works Department, New South Wales. Three anonymous referees made helpful comments on the manuscript.

\section{LITERATURE CITED}

Austen, M. C., Warwick, R. M., Rosado, C. M. (1989). Meiobenthic and macrobenthic community structure along a putative pollution gradient in southern Portugal. Mar. Pollut. Bull 20: 398-405

Bray, J. R., Curtis, J. T. (1957). An ordination of the upland forest communities of southern Wisconsin. Ecol. Monogr. 27: $325-349$

Clarke, K. R. (1993). Non-parametric multivariate analyses of changes in community structure. Aust. J. Ecol. 18(1): $117-143$

Clarke, K. R., Green, R. H. (1988). Statistical design and analysis for a 'biological effects' study. Mar. Ecol. Prog. Ser. 46: $213-226$

Cross, S. F., Ellis, D. V. (1981). Environmental recovery in a marine ecosystem impacted by a sulfite process pulp mill. J. Wat. Pollut. Control Fed. 53: 1339-1346

Ferraro, S. P. Cole, F. A. (1990). Taxonomic level and sample size sufficient for assessing pollution impacts on the Southern California Bight macrobenthos. Mar. Ecol. Prog. Ser. 67: 251-262

Field, J. G., Clarke, K. R., Warwick, R. M. (1982). A practical strategy for analysing multispecies distribution patterns. Mar. Ecol. Prog. Ser. 8: 37-52

Gray, J. S., Aschan, M., Carr, M. R., Clarke, K. R., Green, R. H., Pearson, T H., Rosenberg, R., Warwick, R. M. (1988) Analysis of community attributes of the benthic macrofauna of Frierfjord/Langesundfjord and in a mecocosm experiment. Mar. Ecol. Prog. Ser. 46: 151-165

Gray, J. S., Clarke, K. A., Warwick, R. M., Hobbs, G. (1990). Detection of initial effects of pollution on marine benthos: an example from the Ekofisk and Eldfisk oilfields, North Sea. Mar. Ecol. Prog. Ser. 66: 285-299

Heip, P. M., Warwick, R. M., Carr, M. R., Herman, P. M. J., Huys, R., Smol, N., Van Holsbeke, K. (1988). Analysis of community attributes of the benthic meiofauna of Frierfjord/Langesundfjord. Mar. Ecol. Prog. Ser. 46: $171-180$

Herman, P. M., Heip, C. (1988). On the use of meiofauna in ecological monitoring: who needs taxonomy? Mar. Pollut. Bull. 19: 665-668

Hoare, R., Hiscock, K. (1974). An ecological survey of the rocky coast adjacent to a bromine extraction works. Estuar. coast. mar. Sci. 2: 329-348

Hurlbert, S. J. (1984). Pseudoreplication and the design of ecological field experiments. Ecol. Monogr. 54: 187-211

Jones, D. J. (1972). Changes in the ecological balance of invertebrate communities in the kelp holdfast habitat in some North Sea waters. Helgoländer wiss. Meeresunters. 23: $118-122$

Jones, D. J. (1973). Variation in the trophic structure and species composition of some invertebrate communities in polluted kelp forests in the North Sea. Mar. Biol. 20: 351-365

Kirkman, H. (1981). The first year in the life history and the survival of the juvenile marine macrophyte Ecklonia radiata. J. exp. mar. Biol. Ecol. 55: 243-254

Novacek, I. (1981). Stipe growth rings in Ecklonia radiata. Br. phycol. J 16: 363-371

Ojeda, F. P., Santelices, B. (1984). Invertebrate communities in holdfasts of the kelp Macrocystis pyrifera from southern Chile Mar. Ecol. Prog. Ser 16: 65-73

Pearson, T H., Rosenberg, R. (1978). Macrobenthic succession in relation to organic enrichment and pollution of the marine environment. Oceanogr. mar. Biol. A. Rev. 16: $229-311$

Rosenberg, R. (1973). Succession in benthic macroalgae in a Swedish fjord subsequent to the closure of a sulphite pulp mill. Oikos 24: 244-258

Smith, S. D. A., Simpson, R. D. (1992). Monitoring the shallow sublittoral using the fauna of kelp (Ecklonia radiata) holdfasts. Mar. Pollut. Bull. 24: 46-52

Underwood, A. J. (1981). Techniques of analysis of variance in experimental marine biology and ecology. Oceanogr. mar. Biol. A. Rev, 19: 513-605

Underwood, A. J. (1991). Beyond BACI: experimental designs for detecting human environmental impacts on temporal variations in natural populations. Aust. J. mar. Freshwat. Res. 42: 569-587

Warwick, R. M. (1988a). Analysis of community attributes of the macrobenthos of Frierfjord/Langesundfjord at taxonomic levels higher than species. Mar. Ecol. Prog. Ser. 46: $167-170$

Warwick, R. M. (1988b). The level of taxonomic discrimination required to detect pollution effects on marine benthic communities. Mar. Pollut. Bull. 19: 259-268

Warwick, R. M. (1993). Environmental impact studies on marine communities: pragmatical considerations. Aust. J. Ecol. 18(1): $63-80$

Warwick, R. M., Clarke, K. R., Suharsono (1990a). A statistical 
analysis of coral community response to the 1982-83 El Niño in the Thousand Islands, Indonesia. Coral Reefs 8: $171-179$

Warwick, R. M., Platt, H. M., Clarke, K. R., Agard, J., Gobin,

This article was submitted to the editor
J. (1990b). Analysis of macrobenthic and meiobenthic community structure in relation to pollution and disturbance in Hamilton Harbour, Bermuda. J. exp. mar. Biol. Ecol. 138: 119-142

Manuscript first received: December 8, 1992

Revised version accepted: March 2, 1993 